\title{
Una nueva perspectiva para el constitucionalismo comparado: El análisis cultural del estado de derecho occidental*
}

\author{
Paul W. Kabn**
}

\section{RESUMEN}

Este ensayo reflexiona acerca de los desafíos de comprender el estado de derecho como una forma de vida. Para ello aborda la importancia de entender la comparación entre ordenamientos constitucionales no como una comparación técnica entre estructuras y procedimientos de derecho público, sino como distintas variaciones de un tema perenne en la cultura jurídica occidental: la antinomia entre razón y voluntad.

Estado de derecho - cultura jurídica - constitucionalismo comparado

Comparative constitutionalism in a new key: the cultural study of the Western rule of law

\begin{abstract}
This essay reflects upon the challenges that arise from understanding the rule of law as a form of life. To that end, it explores the importance of understanding the comparison between constitutional orders not as a technical comparison between public law structures and procedures, but as different variations on a perennial theme within Western legal culture: the antinomy between reason and will.
\end{abstract}

Rule of law - legal culture - comparative constitutionalism

* Profesor Titular de Derecho y Humanidades y Director del Centro Orville de Derechos Humanos de la Escuela de Derecho de Yale. Trabajo originalmente publicado en Michigan Law Review No 101, pp. 2677-2705.

Artículo recibido el 30 de octubre de 2015 y aceptado para su publicación el 20 de enero de 2016.

** Traducción de Pablo Marshall Barberán y Fernando Muñoz León. 

1 derecho es un sistema simbólico que estructura la imaginación política. El "estado de derecho" (rule of law) es una expresión que resume toda una práctica cultural constitutiva de una comprensión particular del tiempo y el espacio, de los sujetos y grupos, así como de la autoridad y la legitimidad. Es una manera de proyectar, mantener, y descubrir significados en el mundo de los acontecimientos históricos y de las posibilidades políticas. ${ }^{1}$ El estado de derecho -en contraposición a las técnicas de la abogacía- no es un patrimonio exclusivo de los abogados. Se trata de una caracterización de la comunidad política, que opera como una percepción pública tanto descriptiva como normativamente. La nuestra, creemos, es una nación sujeta al derecho, y el derecho es una medida normativa de todo lo que esta puede hacer.

Que la comunidad política deba expresarse en términos de un estado de derecho es una creencia que ha estado presente desde la fundación revolucionaria de la nación. El fin de la Revolución había de ser un estado de derecho. México pudo haber buscado institucionalizar la revolución ${ }^{2}$. En Estados Unidos, con la abolición de la monarquía, el derecho debía ocupar el lugar del rey ${ }^{3}$. En nuestro mito fundacional, Revolución y Constitución están estrechamente unidas, ambas siendo expresiones vinculadas a la soberanía popular. Las fuentes históricas en que esta comprensión del derecho se basa no son técnicas, sino accesibles para todos. Ellas tienen sus raíces en concepciones religiosas del sentido último de la vida y en concepciones ilustradas acerca del perfeccionismo racional. El estado de derecho es nuestra religión cívica y existe justamente en la intersección de la fe y la razón.

Asumiendo que el estado de derecho es un fenómeno cultural, entonces no hay una base a priori para creer que aquello que sea verdad en los Estados Unidos -sus prácticas y creencias acerca del derecho- lo sea también en otros lugares. Las formas del derecho pueden ser tan diversas como lo sean las de la religión o el arte: las prácticas culturales de una comunidad son solo eso, por lo que no permiten construir afirmaciones de carácter universal. Por supuesto que, al igual que como ocurre con otras prácticas culturales, el estado de derecho no surgió de la nada. El estado de derecho estadounidense está situado dentro de una tradición occidental más amplia. Es una formación particular de lo históricamente posible ${ }^{4}$. Las prácticas y creencias que se heredan, sin embargo, nunca apuntan en una sola dirección; nunca tienen la coherencia de un sistema racionalmente ordenado o causalmente determinado.

A pesar de compartir una historia de práctica religiosa y de ciencia con el resto de Occidente, hay evidencia sustancial para sugerir que la moderna cultura estadounidense sobre el estado de derecho es un tanto diferente. Lo más evidente para la academia

${ }^{1}$ Véase Paul Kahn, The Cultural Study of Law: Reconstructing Legal Scholarship (1999) [de aquí en adelante, Kahn, Cultural Study of Law]; Paul Kahn, The Reign of Law: Marbury v. Madison y la Constitución de Estados Unidos (1997) [de aquí en adelante, Kahn, Reign of Law].

${ }^{2}$ El Partido Revolucionario Institucional (PRI) se mantuvo en el gobierno desde 1929 a 2000.

${ }^{3}$ Véase Thomas Paine, “Common Sense” (1776), en Political Writings 28 (B. Kuklich ed., 1989).

${ }^{4}$ Apropiándome de un concepto de Michel Foucault, he llamado a este horizonte conceptual heredado el 'a priori histórico'. Véase Kahn, Cultural Study of Law, supra nota 1, 36. 
jurídica contemporánea es la profunda resistencia dentro de la práctica constitucional estadounidense a aceptar argumentos que apelen al derecho internacional o comparado. Nuestras prácticas en este sentido son notablemente diferentes de las de otras democracias constitucionales. Mientras que en otros lugares se está llevando a cabo un discurso constitucional transnacional, los estadounidenses están decididos a ubicar su discurso constitucional dentro de su propio texto y su propia narrativa histórica. La preocupación estadounidense respecto de la "intención original", por ejemplo, aparece simplemente irracional -una especie de fetichismo legal- para el resto del mundo. ¿Por qué debemos preocupamos más por la intención de los Padres Fundadores-que han estado por largo tiempo muertos y son culturalmente muy distantes de nosotros-que sobre la comprensión que tienen jueces que son nuestros contemporáneos y que luchan con el mismo tipo de problemas sobre cómo gobernar un moderno estado de bienestar en países con los que debemos construir un ordenamiento jurídico global justo y eficiente? No existe una respuesta para esta pregunta que esté directamente basada en principios, si con ello queremos referirnos a una respuesta que sea accesible a aquellos que se sitúan fuera de nuestra propia cultura. Solo tenemos un conjunto de prácticas y creencias conforme a las que nosotros podemos entender lo que somos.

Un enfoque cultural parece recomendar alejarse del resto del mundo. ¿Por qué, entonces, debería abordar un asunto como el constitucionalismo comparado? No únicamente por el valor intrínseco de las reformas legales. La búsqueda de las reformas legales es el elemento más destacado del estudio contemporáneo del derecho. El académico, así, se pregunta “¿cómo debería ser el derecho?”5. Sin embargo, una cultura no está tratando de ser otra cosa que lo de hecho es ${ }^{6}$. Por supuesto, una cultura tiene sus propias normas internas -tendrá incluso normas sobre normas-, pero desde la perspectiva de los estudios culturales, esas normas son los fenómenos que deben explicarse, no metas que deban alcanzarse. De esta manera, un enfoque cultural comienza separando el estudio del derecho de la práctica de su reforma. Lo mismo sucede en su aproximación al constitucionalismo comparado. El objetivo no puede ser determinar cuáles son las prácticas constitucionales más eficientes o eficaces; tampoco puede consistir en perseguir una concepción de la justicia. El trabajo comparativo puede ser de hecho útil en la búsqueda de la reforma legal, pero la búsqueda de la reforma socava el objetivo de una aproximación cultural al derecho. Para volver a un ejemplo que he utilizado en otra parte: no estudiamos las religiones comparadas con el fin de averiguar qué religión es la mejor o con el objetivo de reformar nuestro propio conjunto de creencias ${ }^{7}$.

El análisis cultural, de todas formas, debe estar interesado en el constitucionalismo comparado por la misma razón que el estudio de nuestras propias prácticas y creencias religiosas puede ser útilmente iluminado mediante el estudio de las prácticas y creencias de otros pueblos. Si el estado de derecho es una práctica cultural -para nosotros, una práctica completamente naturalizada- entonces lo que pasa inadvertido en nuestras prácticas

\footnotetext{
${ }^{5}$ Véase Roberto Unger, What Should Legal Analysis Become? (1996).

${ }^{6}$ Véase Kahn, Cultural Study of Law, supra nota 1, 92-97.

${ }^{7}$ Kahn, Cultural Study of Law, supra nota 1, 2.
} 
puede hacerse visible mediante el contraste con otras prácticas culturales del derecho. Esta es una pregunta particularmente importante en la actualidad, debido a que uno de los aspectos propios de la globalización es el esfuerzo por avanzar hacia un modelo común de constitucionalismo. Un enfoque cultural puede permitirnos conocer los aspectos más importantes de los diferentes constitucionalismos existentes. Puede ayudar a comprender mejor lo que está en juego en varios esfuerzos de reforma y en el movimiento hacia la globalización. Lo más importante es que puede ayudarnos a entender quiénes somos, pese a que no puede, sin embargo, decirnos si debemos seguir siendo lo que hemos sido.

Jueces constitucionales de todo el mundo a menudo parecen creer que están inmersos en una sola conversación, una transnacional, con sus homólogos de otros países. Escriben sus opiniones el uno para el otro -participando libremente en un trabajo colectivo- como también lo hacen para su propia ciudadanía. Este es un comparativismo de modo reformista y es tanto el discurso dominante de la práctica contemporánea del constitucionalismo comparado como la principal fuente de interés en este campo. Este enfoque está profundamente a contrapelo de nuestra práctica constitucional. El discurso constitucional estadounidense no forma parte de este discurso transnacional; esto a pesar de que los profesores de derecho estadounidenses que comparten la aspiración liberal para un orden jurídico global están haciendo todo lo posible para impulsar la entrada de los Estados Unidos en esta práctica discursiva.

Un enfoque cultural puede ser un poderoso antídoto frente a este ideal liberal que aspira a un gobierno mundial en el marco de un estado de derecho. No necesariamente debido a que defiende una visión normativa alternativa -pues no aboga por la diversidad frente a la uniformidad; de hecho no aboga por ninguna posición-, sino más bien porque su ambición es solo a mostrar que el campo sobre el que actúan quienes buscan la reforma legal es más complejo de lo que ellos se imaginan; que no todos los valores en juego responden a las exigencias de la razón, ni que pueden alinearse en una dirección particular. Si deben o no hacerlo es una pregunta diferente. Esa pregunta no es más accesible para el académico que la cuestión de si las personas deben enamorarse, deben encontrar determinadas obras de arte hermosas, o deben creer en ciertos dioses. El estado de derecho es tan fundamental para la identidad individual y grupal como estas otras prácticas culturales. Los profesores de derecho pueden, por supuesto, tener una posición acerca de quiénes debemos ser como individuos y ciudadanos. Pero su pretensión de un conocimiento jurídico experto no les da una posición privilegiada en ese debate. Tal vez esta es la lección más importante que un enfoque cultural tiene para ofrecer: los reclamos de experticia legal no ofrecen un atajo para la reforma política. Si los estadounidenses deberían ser una cosa distinta de los que son, cambiarlos tomará bastante más que la apelación a la reforma legal.

\section{UBiCANDO LO CULTURAL: DE LO UNIVERSAL A LO PARTICULAR}

El enfoque cultural hacia el constitucionalismo comparado se encuentra justo en el extremo opuesto al de la mayoría de quienes estudian el derecho desde las ciencias sociales. El enfoque de estos últimos es aproximarse a los tribunales, incluidos los tribunales 
constitucionales, desde la perspectiva del despliegue institucional de poder político. Los tribunales interactúan con otras instituciones gubernamentales en la elaboración de las políticas públicas y, en consecuencia, deben ser estudiados desde la perspectiva de las políticas que ayudan a producir ${ }^{8}$. Ese estudio tiene tanto un componente interno como un componente externo.

Al igual que cualquier otro actor en el proceso de formulación de políticas públicas, los tribunales quieren tener éxito. Esto significa, en parte, que toman las medidas que toman porque ellas van a legitimar su propio papel. El comportamiento judicial, en ese entendido, se dirige simultáneamente a la producción de políticas públicas y a asegurarse un papel institucional. Para una institución sin recursos materiales la eficacia está estrechamente ligada a la legitimidad. Desde esta perspectiva, podemos entender la expansión y racionalización de la jurisdicción, así como sus normas internas de coherencia, explicación e intertextualidad ${ }^{9}$. De hecho, una de las lecciones de Marbury ${ }^{10}$ es que la manera en que la Corte afirma "mirar" la Constitución es en sí misma una forma de construcción de la autoridad de la Corte frente otros actores políticos y ante los ojos de la opinión pública. Podemos llamar a esto las necesidades “internas” de la judicatura.

Además de estudiar el interés institucional propio de los tribunales, también debe explorarse las oportunidades que los tribunales otorgan a los "actores" -individuos y grupos- para perseguir sus propias agendas, o para bloquear la realización de agendas ajenas. Personas y grupos harán uso de cualquier institución que esté disponible con el fin de avanzar en sus intereses ${ }^{11}$, recurriendo a los tribunales cuando haya alguna ventaja en hacerlo. Su interés, por cierto, no está en reivindicar o afirmar el estado de derecho, sino en perseguir el cumplimiento de fines que son externos al sistema judicial. Los tribunales pueden convertirse en actores políticos eficaces cuando entregan los medios para compensar reveses y derrotas producidas en las instancias ordinarias para la determinación de las políticas públicas del Estado, ya sean estas legislativas o administrativas.

Ambos enfoques están interesados en entender cómo un tribunal constitucional contribuye a la formación de una concreta política regulatoria, por ejemplo, la legislación laboral o de telecomunicaciones. Desde el primer enfoque estaríamos interesados en estudiar el crecimiento de la doctrina: cómo un caso es seguido por otro, y en cómo un tribunal responde a las decisiones de otros tribunales. También querríamos dar seguimiento a la forma en que las decisiones judiciales dan forma a la percepción de qué es posible dentro de otras instituciones. Por último, querríamos mirar cómo las facciones en pugna utilizan la disponibilidad de los tribunales y argumentos constitucionales como un medio que sirva a las políticas que buscan perseguir. Desde las ciencias sociales se cree que estos dos enfoques serían apropiados para al estudio de cualquier institución

${ }^{8}$ Véase, p. ej., Martin Shapiro y Alec Stone Sweet, On Law, Politics, and Judicialization 3-13 (2002).

${ }^{9}$ Véase Alec Stone Sweet, Path Dependence, Precedent, and Judicial Power, en On Law, Politics, and Judicialization, supra nota 8, 112-35.

${ }^{10}$ Marbury v. Madison, 5 U.S. (1 Cranch) 137 (1803).

${ }^{11}$ Véase Martin Shapiro, Law and Politics in the Supreme Court: New Approaches to Political Jurisprudence (1964). 
política. Por ejemplo, podríamos hacer las mismas preguntas acerca de la función legislativa en la formación de una política pública, distinguiendo entre las necesidades de los legisladores - para conseguir ser reelectos y expandir su influencia- y las de los grupos de interés que pretenden influir en la legislación. Para las ciencias sociales, los tribunales deben ser estudiados como parte del conjunto del fenómeno político.

Para el cientista político, no hay nada acerca de los tribunales que no pueda ser aprendido por las técnicas de investigación comunes de las ciencias sociales. Los tribunales pueden creer que están haciendo algo diferente de las legislaturas -pueden utilizar un lenguaje jurídico en lugar de uno económico, de derechos en lugar de intereses y de constituciones en lugar de elecciones-, pero el cientista social afirmará que los tribunales no son más que otro espacio para la impugnación y la construcción de las políticas públicas. La pregunta sobre cómo los tribunales hacen esto importa mucho menos que el hecho de que lo hagan. Por supuesto, los cientistas sociales tienden a estar en desacuerdo respecto del alcance de las investigaciones, las metodologías apropiadas, y la gama de factores que deben tenerse en cuenta. El enfoque de Alec Stone Sweet, por ejemplo, se caracteriza por la amplitud de sus técnicas metodológicas y la gama de intereses que considera. Se da cuenta de que la juridificación de las políticas públicas se lleva a cabo tanto dentro como fuera de los tribunales, y que los intereses no son independientes de las instituciones y de las reglas que las instituciones despliegan para resolver disputas ${ }^{12}$. De todas formas, las preguntas comparativas que son interesantes para los cientistas sociales son fundamentalmente políticas: ¿Cómo y en qué contexto los tribunales constitucionales crean para sí mismos un papel sustancial en la formulación de políticas públicas? ¿Cómo se destacan en relación con otras instituciones? ¿Qué intereses se benefician por ese papel?

El jurista interesado en el constitucionalismo comparado se resiste a cualquier afirmación que signifique una disolución de la distinción entre el derecho y la política. En esto, se definen en contraste del enfoque de la ciencia política. El carácter distintivo del derecho como disciplina se basa en la afirmación de esta diferencia: el derecho puede ser producido por la política, pero no puede ser reducido meramente a otro foro para la acción de una política impulsada por intereses y poder $^{13}$. A pesar de que esta clase de académicos se resiste a fundar su trabajo comparativo en normas políticas, aún así necesita un estándar común que le permita aproximarse a sistemas constitucionales diferentes. De hecho, la utilidad de la empresa comparativa depende del hecho de contar con una medida de este tipo. Al igual que prácticamente todos los demás estudioso del derecho, la medida común de los

${ }^{12}$ Véase, por ejemplo, Alec Stone Sweet, Governing With Judges: Constitutional Politics In Europe (2000); Alec Stone Sweet \& Thomas C. Brunell, Constructing a Supranational Constitution: Dispute Resolution and Governance in the European Community, 92 Am. Pol. Sci. Rev. 63 (1998).

13 Periódicamente surgen movimientos legales que desafían esta distinción: el más famoso, los realistas jurídicos; el más reciente, el movimiento de los Critical Legal Studies. Estos grupos disidentes nunca duran demasiado, debido a que su propio compromiso con la legalidad, y con las posibilidades que ofrece la legalidad, son demasiado grandes. Los realistas legales fueron literalmente llevados de vuelta al redil por sus nombramientos en la judicatura y su éxito en la academia. Los Crits se vieron comprometidos con reclamos jurídicos y carentes de poder en sus aventuras en la política. 
comparativistas es la ambición de reformar el estado de derecho bajo la guía de la razón. Su aspiración es expulsar del sistema jurídico-constitucional los aspectos irracionales que solo pueden explicarse por los accidentes de la historia o la desgracia del error. El objetivo último del estudio del derecho ha de ser un conjunto de sugerencias programáticas.

Otro nombre para esas deficiencias identificadas por los estudiosos del derecho comparado es "política”. Aquí, los profesores de derecho se definen a sí mismos en contraste al enfoque de la ciencia política. Para el estudioso del derecho constitucional, los tribunales tienen una misión más importante que simplemente ofrecer un foro alternativo para una política de grupos de interés o el ampliar su propia influencia. Los tribunales representan principios, la razón, derechos o valores perdurables. Diferentes estudiosos utilizarán un lenguaje diferente para referirse a ello, pero lo que todos tienen en común es el paso expedito de un discurso particularizado a un discurso transnacional: la razón no puede significar una cosa en un lugar y otra cosa en otro lugar. Los derechos son universales. ¿Quién puede oponerse a tales valores perdurables como la libertad, la igualdad y el debido proceso? El académico constitucionalista-comparativista toma con gusto el papel de articulador de aquellas normas que servirán para fundar un nuevo orden jurídico transnacional. Personifica una actitud liberal hacia el estado de derecho que expresa un genuino escepticismo, si no abierta hostilidad, hacia la particularidad de la política nacional.

Este contraste de enfoques en relación con el constitucionalismo comparado refleja una división fundamental dentro de la tradición ilustrada sobre el lugar que corresponde a una ciencia práctica de la política. La mayoría de los cientistas sociales localizan la ciencia de la política -la razón- en su propio ámbito de estudio. Los objetivos de ese estudio -las prácticas políticas de una comunidad- responden a intereses y poder. Para estos académicos es una especie de confusión hegeliana el sugerir que el dominio de la política consiste en el desenvolvimiento autocontenido de la razón. La razón es lo que el cientista social trae consigo a la situación de conflicto de intereses en que consiste la política. Reformar el desorden de la política es posible en los márgenes, pero es un error fundamental pensar que la política pueda ser un ejercicio de racionalidad. La política, incluso en su forma judicial, es solo el medio para la satisfacción de intereses que son, en su mayor parte, exógenos a las instituciones disponibles para su realización. El constitucionalismo comparado, por tanto, es el estudio de las formas del poder. La razón a la que se apela es la razón de la categorización, la generalización y la predicción. Estas son patrimonio del académico, y son de poco o ningún interés para los actores políticos ${ }^{14}$. Cualesquiera sean las regularidades que aparezcan en el análisis de los fenómenos, ellas serán el fruto de intereses comunes, que pueden ser más o menos extensos.

Los profesores de derecho interesados en el derecho constitucional comparado no aceptan la premisa de que la razón existe y debe permanecer fuera de la política ${ }^{15}$. Para

${ }^{14}$ Cuando el académico cree que su conocimiento le califica para un papel político, se compromete a una especie de vanguardismo, que no tiene un buen historial, partiendo por la misión de Platón en Siracusa.

${ }^{15}$ Debido a que Stone Sweet coloca la elaboración de razonamientos judiciales en el centro de su relato sobre el desarrollo político y la eficacia de los tribunales constitucionales, su trabajo sobrepasa esta división e incluso puede estar más cerca del de los juristas. 
ellos, el papel de la Constitución consiste en someter la política a las normas superiores de la razón. Una Constitución expresa el ordenamiento razonable de la comunidad política; ella consiste en hacer presente la razón dentro del funcionamiento interno del propio Estado. Esto no es una cuestión de describir un texto constitucional en particular o de analizar los orígenes de ese texto -que de hecho podría apuntar a la comprensión de los cientistas políticos-. Es, más bien, la idea que guía al constitucionalismo moderno y a las decisiones constitucionales: la razón misma constituye la constitución implícita hacia la que cada decisión se dirige. Los profesores de derecho creen que si no podemos concebir al derecho separado de la política, estaríamos estudiando un fracaso del Estado de Derecho. ¿Quién en el Estado constitucional está dispuesto a decir que la Constitución nos exige "irracionalidad” o que demanda la violación de los derechos fundamentales o importantes principios morales? Por supuesto, grupos de interés poderosos se las arreglarán para afianzar sus propios intereses en la Constitución, pero eso implica una deficiencia en el marco del Estado de Derecho y es justamente un objeto apropiado para una futura reforma ${ }^{16}$.

Desde la perspectiva del profesor de derecho constitucional, entonces, el ideal de la razón actúa dentro del objeto mismo de su estudio ${ }^{17}$. La razón ya se encuentra ahí, y la contribución académica, entonces, es solamente aclarar lo que dicha razón exige. La ambición de su estudio es no entender el derecho mediante la implementación de herramientas de investigación que no son en sí mismas parte del objeto de estudio, sino más bien determinar "lo que debe ser el derecho". Debido a que la Constitución concibe a la razón dentro del Estado, la distinción entre lo que el derecho es y lo que debería ser es tan estrecha que arriesga desaparecer en la autocomprensión del académico. El estado de derecho es y debe ser el gobierno de la razón. Reforma, en consecuencia, no es un proceso que afecta al derecho desde el exterior, sino que es un desarrollo interno del derecho ${ }^{18}$.

Sería exagerado decir del constitucionalismo comparado que su ambición es encontrar la ciencia oculta de constitucionalismo que debería unir a todas las constituciones liberales como variaciones acerca de un mismo tema -pero no sería exagerar demasiado-. De hecho, si uno contrasta los constitucionalistas estadounidenses con los constitucionalistas europeos y latinoamericanos, la ambición de estos últimos de situar los estudios comparativos dentro de la ciencia del derecho no se oculta en absoluto.

${ }^{16}$ En la historia constitucional de los Estados Unidos el mejor ejemplo es la protección constitucional de la esclavitud hasta la aprobación de las enmiendas de la Guerra Civil.

${ }^{17}$ El derecho consuetudinario británico fue, durante mucho tiempo, capaz de ofrecer una base para la razón dentro del Estado. El movimiento hacia el constitucionalismo escrito en Gran Bretaña contemporánea sugiere un conflicto más profundo sobre el lugar de la razón; es decir, un debate sobre el papel de la historia y la experiencia contemporánea en la identificación de la razón. Este es un debate que nunca deja de existir, sino que vuelve a aparecer en cuestiones relativas a la función de los precedentes en la interpretación de un texto constitucional: ¿Por qué las comprensiones del pasado deben ser favorecidas sobre razonamiento contemporáneo?

18 Véase Kahn, Cultural Study of Law, supra nota 1, 7-18 
Si nos preguntamos cuál es la estructura organizativa de esta creencia en un constitucionalismo de la razón objetiva y universal, nos encontramos con una doctrina de los derechos y una teoría de la legitimidad política. La primera localiza el constitucionalismo comparado en el discurso de los derechos humanos; la segunda, la sitúa en la tradición moderna del contrato social. El constitucionalismo contemporáneo es el heredero de una doble corriente de pensamiento. La ciencia de la política del siglo XVIII era una ciencia mecanicista de las instituciones. Estas instituciones mediarían entre los orígenes sociocontractualistas del Estado legítimo y el ejercicio de autoridad por parte de los agentes del Estado. El objetivo era estructurar instituciones de tal manera que sirvieran para frenar el posible abuso del poder político creado por el propio contrato social ${ }^{19}$. La ciencia de la política del siglo XX, por otro lado, está preocupada de los derechos humanos universales. La protección contra el abuso de poder aparece ahora no tanto como una función del diseño institucional, sino como una determinación de un conjunto de pretensiones jurídicas que protegen al individuo como sujeto portador de derechos ${ }^{20}$.

Los profesores de derecho entienden que los tribunales constitucionales trabajan en un conjunto común de problemas relacionados principalmente con derechos y legitimidad. El académico mira a los diversos tribunales constitucionales nacionales para aprender de la experiencia y los argumentos de todos ellos. Cada Estado liberal moderno se enfrenta al mismo conjunto de temas constitucionales -derecho a la intimidad, a la libre expresión, al debido proceso y al bienestar social, por una parte, y a cuestiones de diseño institucional legítimo, por otro-. Debido a que los tribunales abordan estos temas en un orden que es enteramente accidental, un tribunal constitucional puede hacer uso de la investigación y el razonamiento de otro tribunal que puede haber enfrentado un problema similar con anterioridad. La comparación, por lo tanto, viene a competir con los precedentes como fuente material del razonamiento jurídico. Si la autoridad de la decisión descansa sobre su apelación a la razón este enfoque parece no solo natural sino esencial. Se basa en el modelo de investigación de otras ciencias. Ningún programa de investigación puede transformar su pasado en un fetiche; por el contrario, estos deben permanecer abiertos a nuevos "descubrimientos" donde quiera que estos se produzcan.

Estos dos enfoques -el del cientista social y el del profesor de derecho- no logran captar mucho de lo que es esencial para la comprensión del carácter del estado de derecho estadounidense. Más importante aún, no logran entender la forma en que la Corte Suprema forma parte tanto funcional como institucionalmente de las creencias sobre el estado de derecho. El papel más importante de la Corte no es hacer política, ni

${ }^{19}$ En esto, El Federalista sigue siendo el texto clásico, con su énfasis en el federalismo y la separación de poderes.

${ }^{20}$ Una característica de la teoría constitucional contemporánea estadounidense es el esfuerzo por vincular estas dos fuentes. Vemos, por ejemplo, los argumentos de que el federalismo o la separación de poderes en realidad tienen sus efectos en la protección de los derechos individuales. Véase, por ejemplo, Estados Unidos v. López, 514 EE.UU. 549, 575-79 (1995) (Kennedy, J., concurriendo). Contrástese esto con el clásico entendimiento de la separación de poderes como una doctrina negativa que protege derechos mediante la desactivación de gobierno. Véase, por ejemplo, Youngstown Sheet E Tube Co. v. Sawyer, 343 EE.UU. 579 , 613-14 (1952) (Frankfurter, J., concurriendo). 
tampoco alcanzar los objetivos de una ciencia jurídica racional - aunque seguramente la Corte hace política y está sujeta a la crítica de la razón-. Antes que eso, el principal rol de la Corte Suprema es construir y mantener una comprensión de nuestro sistema de gobierno que sea expresión del estado de derecho. Esta función opera, en su mayor parte, con independencia de los resultados a los que la Corte llega, incluso en los casos controvertidos. Por ejemplo, cuando la Corte revirtió Roe v. Wade ${ }^{21}$ lo hizo en nombre del Estado de Derecho. Su decisión estaría celebrando la "recuperación” del derecho de la misma forma en que Adarand celebra el estado de derecho cuando revierte Metro Broadcasting ${ }^{22}$. Esto no significa que la Corte pueda decir lo que quiera, pero en relación con cualquier caso controversial que pueda llegar a la Corte, hay suficientes insumos jurídicos para apoyar tanto la confirmación como la reversión del precedente. Así, las opiniones disidentes podrían ser opiniones mayoritarias y no podemos distinguirlas únicamente en función de estándares de razonamiento jurídico y Estado de Derecho.

Este papel de la Corte no depende de que los resultados sean correctos, ni depende de que apoye los intereses de algunos grupos y no de otros. Más bien, el trabajo de la Corte consiste en apoyar y mantener una cierta construcción cultural. Esto solo puede entenderse si nos acercamos al estado de derecho como lo haríamos con cualquier otro conjunto de creencias culturales: religiosas, míticas, estéticas, o incluso científicas. No podemos preguntarnos acerca de la verdad jurídica ni sobre la utilidad del derecho si nuestra ambición es entender al derecho como una visión del mundo. En lugar de las herramientas de la ciencia o de la autoelaboración de la razón, tenemos que incorporar al estudio del derecho las herramientas de la interpretación cultural.

Solo cuando entendemos que nuestra propia Corte Suprema se involucra en la actividad única de mantener la creencia de la ciudadanía estadounidense en que su participación en una soberanía popular se expresa en y por medio del estado de derecho es que podemos empezar a comprender el inmenso poder de esta institución. Ese poder tiene su punto simbólico de origen en el caso Marbury $v$. Madison ${ }^{23}$ y su más vívida expresión en el reciente Bush v. Gore ${ }^{24}$. Marbury articula una visión del estado de derecho inclusive cuando la Corte manifiesta ser un actor político débil. Doscientos años más tarde, esa misma visión opera como la religión cívica del Estado-nación estadounidense ${ }^{25}$.

La Corte como el guardián de ese orden simbólico ejerce un poder incuestionable. Tanto es así que puede decidir que el Presidente de los Estados Unidos es la persona que perdió en el voto popular. Los estadounidenses no tienen ninguna teoría de gobierno legítimo más allá de la toma de decisiones democrática limitada por un régimen de derechos individuales -si pensamos que por teoría podemos entender una apelación a principios y argumentos racionales basados en estos principios-. Literalmente no tenían

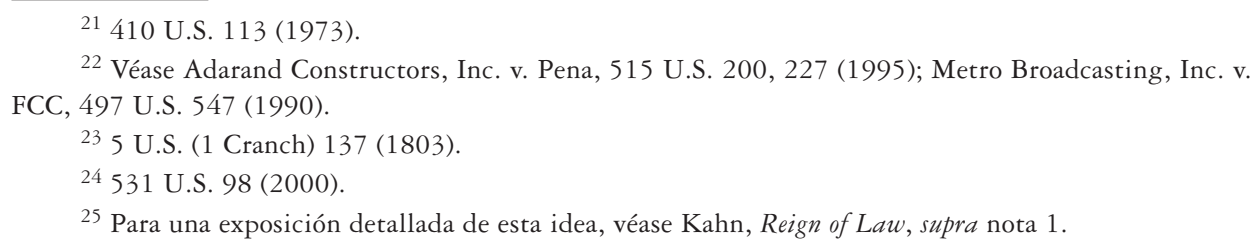


una teoría que permitiera entender cómo Bush podría ser un presidente legítimo. De haber sucedido lo mismo en otro lugar, ello habría sido tomado como evidencia de una antidemocrática frustración de la voluntad legítima del pueblo. Sin embargo, los estadounidenses tienen una profunda fe en la Constitución y en la Corte como la voz del pueblo soberano. Cuando debe elegirse entre una teoría de la legitimidad y una afirmación de su orden simbólico, simplemente no hay competencia. Ni siquiera la parte perdedora podría seriamente quejarse del resultado. Ellos también debieron afirmar que la nuestra es una nación sujeta a derecho y que la decisión de la Corte es la última palabra sobre lo que significa la Constitución.

Los estadounidenses son feligreses dispuestos en este templo de la creencia. Cuando la Corte habló, el proceso eleccionario había terminado. Esto fue así a pesar de que pocos fuera de la academia afirman haber entendido las palabras que se dijeron, y aunque la mayoría de los académicos pensó que no fue una opinión convincente. No hubo recurso adicional ante el tribunal de la opinión política. Si nos acercamos al tema del constitucionalismo comparado con esta experiencia en mente, se abren una nueva serie de preguntas: nos preguntamos si los tribunales constitucionales en otros lugares se dedican de manera similar a la empresa mítica de mantener una comunidad de fe. Si es así, tenemos que investigar cuáles son los elementos de esa fe y de qué forma se asemejan a nuestra propia fe en el estado de derecho.

Tómese como un ejemplo simple la práctica de nombramiento de los jueces en los Estados Unidos, particularmente de los jueces de la Corte Suprema. Un candidato se selecciona normalmente sobre la base de las creencias acerca de cómo él o ella probablemente votará. La selección es un proceso altamente político en el que los intereses son evaluados y los grupos de interés son escuchados. Las reacciones ante el candidato -tanto a favor como en contra- se basan en similar evaluación de intereses. Sin embargo, invertimos una gran cantidad de esfuerzo y recursos en negar el carácter político de este proceso de nombramiento. El Presidente anunciará que escogió el mejor jurista y que solamente desea un juez que persiga el estado de derecho ${ }^{26}$. El candidato se negará firmemente a comentar acerca de cómo podría votar respecto de cualquier cuestión que pueda surgir ante la Corte. En vez, escuchamos declaraciones de lealtad al derecho y de buena fe en el estudio de los escritos y argumentos. Como juez constitucional, el candidato nos asegura que responderá únicamente al derecho, del cual será un instrumento. Lo que sea que él o ella pueda haber sentido y creído previamente, la vida comenzará de nuevo al vestirse con la capa negra de la Corte.

La confirmación del juez es literalmente un ritual transformador, un acto de conversión, mediante el cual un individuo que había sido un ser político se convierte en un instrumento del estado de derecho. Nada sobrevive en el paso de un mundo a otro. La persona nombrada nacerá de nuevo, despojado de sus viejas lealtades partidistas, afiliaciones institucionales, contactos, e incluso amistades. Mientras los funcionarios

${ }^{26}$ Véase, por ejemplo, la declaración del presidente Bush sobre la nominación de Clarence Thomas a la Corte Suprema. Nominación de Juez Thomas por el Presidente Bush, disponible en http://www.people.virginia. edu/-govdoc/thomas/nomination.html (visitado por última vez el 8 noviembre de 2003). 
electos traen sus asesores políticos con ellos, un juez constitucional ni siquiera se supone que debería aceptar una llamada telefónica de las personas que le ayudaron a obtener su cargo. Una vez que él o ella entra en el Templo de la Justicia, está literalmente por su cuenta -con la excepción de unos pocos asistentes jurídicos que se caracterizan por su inocencia política- de pie antes de que mysterium tremendum de nuestro orden cívico: la Constitución.

Todos los países se enfrentan al problema de la relación entre sus tribunales y sus instituciones políticas, es decir, entre el derecho y la política. La legitimidad de los tribunales depende de manera importante de la independencia de los jueces respecto de aquellos que ejercen el poder político. A causa del poder de los tribunales constitucionales, el problema es aún más agudo respecto de ellos. Sin embargo, en algunos países el enfoque que se da a este problema no es suprimir sino que hacer explícita la relación entre la creencia política y designación judicial. En Francia, "el criterio más importante para ser nombrado en el Consejo [Constitucional] es la afiliación política, y el Consejo ha estado dominado por los políticos profesionales" ${ }^{27}$. Algo similar ocurre con la organización de la Corte Internacional de Justicia, que no solo sigue un principio de distribución geográfica, sino también garantiza el derecho de cualquier Estado que litiga ante el Tribunal de nombrar uno de los jueces que conocerá del caso $^{28}$.

Por supuesto, esto no significa que la persona nombrada simplemente actúe como representante, prefiriendo los intereses de su partido político o su Estado. La conexión política explícita en el proceso de nombramiento tendría que ser superada en otro punto dentro del proceso judicial. Sin embargo, en los Estados Unidos ni siquiera podemos acercarnos a tal reconocimiento de la intersección entre el derecho y la política. En nuestra construcción cultural, política y derecho se mantienen en lados diferentes de una brecha insalvable, de tal manera que la persona que el juez constitucional ha sido con anterioridad desaparece totalmente una vez que es designado. Él o ella no tienen más conexión con esa vida anterior que la que tiene el sacerdote que recibe la confesión y administra el sacramento.

Esta idea se refleja interesantemente cuando se observa en la primera parte de Marbury, la cuestión de si Marbury tiene derecho a su empleo ${ }^{29}$. La Corte solo puede responder a esa pregunta, respondiendo a la pregunta de si se trata de un Juez de Paz: ¿Ha completado la transición de actor político -Marbury fue un operador del Partido Federalista en Maryland- a un instrumento de la ley? En la conclusión de que su derecho ha sido conferido y que lo que se ha hecho por el derecho no puede ser revertido por la política, los miembros de la Corte están hablando nada menos que de sus propios nombramientos. Es posible que ellos hayan sido en el pasado socios políticos del ahora derrotado presidente Adams, pero ahora ellos existen solamente en el ámbito del derecho.

${ }^{27}$ Alec Stone, The Birth Of Judicial Politics In France: The Constitutional Council In Comparative Perspective 50 (1992).

${ }^{28}$ Estatuto de la Corte Internacional de Justicia, art. 31, disponible en: http: //www.icj-cij.org/cijwww/ ibasicdocuments/ibasictext/ibasicstatute.htm (última visita 8 de noviembre de 2003).

${ }^{29}$ Marbury v. Madison, 5 U.S. (1 Cranch) 137, 154 (1803). 
De hecho, han perdido su voz personal, así como su aspecto político. Marbury no es la voz de John Marshall, exsecretario de Estado federalista, sino la "opinión de la Corte" que puede ser anunciada por Marshall, pero pretende ser la opinión de todos nosotros como miembros del pueblo soberano ${ }^{30}$. Los jueces constitucionales nos dicen que ellos existen completamente dentro del derecho y más allá de la esfera de la política. Eso, al menos, es lo que nos quieren hacer creer, y en su mayor parte es lo que nosotros creemos.

Para nosotros, reconocer la conexión del derecho con la política aparece solo como una forma de una opinión crítica. De hecho, esta es la más común y devastadora crítica que se puede ofrecer de un juez: sus decisiones se fundan políticamente, no jurídicamente. Sin embargo, pese a ser la más devastadora de las críticas, también es completamente ineficaz contra el carácter autónomo del estado de derecho. Porque si vamos un paso más allá, vemos que el ordenamiento jurídico no solo se defiende de este tipo de ataques como un asunto de interés institucional, sino que tiene en su centro un mecanismo para neutralizar esta crítica. Incluso las decisiones que son más criticadas en cuanto son productos de la política se convierten en precedentes que son reconocidos y seguidos en casos futuros. Lo que ha sido política se transforma en derecho, de tal manera que su no seguimiento se convierte en sí mismo un signo de una política fuera de lugar ${ }^{31}$. Esto produce el peculiar ciclo de reacciones de expertos en relación con las decisiones de la Corte. En primer lugar, las decisiones son criticadas por no seguir el derecho existente. Si es así, deben estar basadas en algo que está fuera de la ley, es decir, las creencias políticas de los jueces. En segundo lugar, esas mismas decisiones deben integrarse en una versión completa de lo que es el derecho, que es justo lo que el experto afirma conocer. La decisión de esta manera pasa de ser un objeto de crítica a ser naturalizada dentro del cuerpo del derecho. La Corte, por tanto, produce su propia infalibilidad, siempre y cuando la creencia en el estado de derecho se mantenga. La más conmovedora muestra de este movimiento en los últimos años fue Casey, donde jueces nombrados políticamente con miras a revertir Roe se vieron obligados por los mecanismos internos de razonamiento jurídico a confirmar el precedente ${ }^{32}$. El mismo movimiento que parte desde una aberración y termina en una norma caracteriza a la jurisprudencia reciente de la Corte en relación con el federalismo.

La separación entre derecho y política es asegurada en algunos países por una institucionalización de la idea de experticia jurídica o judicial. Esta institucionalización puede tomar una variedad de formas. Algunos países entrenan a sus jueces separadamente de los abogados de ejercicio libre, y les ofrecen una carrera que se desarrolla totalmente dentro de la judicatura. La experticia en juzgar es vista como una habilidad que se desarrolla

${ }^{30}$ Véase Kahn, Reign of Law, supra nota 1, 209-19.

${ }^{31}$ Esta es la razón por la que la persistencia de la disidencia es un problema para el Estado de Derecho. Un Tribunal que permanece dividido en los mismos temas siempre sugerirá una conexión entre derecho y política. Por otra parte, la práctica estadounidense de la disidencia puede ella misma ser posible gracias a la enorme apuesta en otros medios que buscan la separación del derecho y la política.

${ }^{32}$ Planned Parenthood v. Casey, 505 U.S. 833, 854-64 (1992). 
durante toda una carrera ${ }^{33}$. Otros establecen un comité de expertos para seleccionar a aquellos "más calificados" para ser nombrados jueces. Esta selección tiende a centrarse en aquellos profesionales de mayor éxito ante los tribunales. Francia sigue la primera ruta; Inglaterra, la segunda ${ }^{34}$. Otros países descansan en gran medida en los profesores de derecho. En Israel, los nombramientos de jueces son un producto de un "Comité de Nominaciones" que institucionaliza los ideales de experiencia profesional ${ }^{35}$. Nosotros en Estados Unidos no seguimos ninguno de estos procedimientos ${ }^{36}$. El derecho constitucional no puede aparecer como una ciencia misteriosa en este país. No puede ser la posesión de expertos o funcionarios de carrera.

Al igual que con la relación entre derecho y política, la construcción de la interpretación constitucional requiere suspender voluntariamente la incredulidad. Sabemos que el derecho es una tarea de interpretación erudita y sofisticada, pero sin embargo no puede concebirse como algo inaccesible para quienes carezcan de formación especializada; al menos el derecho constitucional no puede aparecer de esa manera, cualquiera que sea el caso de las áreas más técnicas de la regulación legal ${ }^{37}$. El acusado en el proceso penal, en este sentido, ocupa el lugar de todos y cada uno de nosotros en su relación con el ejercicio de la autoridad legal del Estado: se le leen sus derechos y se le pregunta si entiende lo que se le ha leído.

Muchos Estados de todo el mundo hoy tienen largas constituciones que establecen derecho con gran detalle. Nuestra Constitución sigue siendo un documento breve, del siglo XVIII, escrita en su mayor parte en la lengua vernácula. Sus frases más importantes son simples y directas: "libre ejercicio", "libertad de expresión”, "comandante en jefe”, o "poder legislativo". Por supuesto, el documento ha sido objeto de cientos de años de interpretación esotérica, pero eso es otra cuestión. En este caso, lo que importa es la creencia en la accesibilidad directa de los ciudadanos al texto. Lo que está en juego en esa relación de accesibilidad es la afirmación fundamental del estado de derecho estadounidense: la Constitución expresa la voz del pueblo soberano. Es propiedad del pueblo y no del jurista ${ }^{38}$.

El ciudadano se encuentra con el estado de derecho como súbdito y autor. En su particularidad, es gobernado por el derecho, pero como parte del pueblo soberano es también autor del derecho. Esta relación de la parte al todo, teorizada por Rousseau, se encuentra en la base de la creencia estadounidense en el estado de derecho. Esta

33 Véase John Bell, Principles as Methods of Judicial Selection in France, 61 S. Cal. L. Rev. 1757, 1758 (1988).

${ }^{34}$ En Francia, por supuesto, el Consejo Constitucional no forma parte del poder judicial ordinario y sus designaciones siguen un proceso diferente y más político.

${ }^{35}$ Véase Shimon Shetreet, Justice In Israel: A Study Of The Israeli Judiciary (1994)

${ }^{36}$ El gobierno de Bush recientemente rompió con la práctica de obtener una evaluación formal de los candidatos judiciales de la American Bar Association.

${ }^{37} \mathrm{La}$ existencia de tribunales especiales de carácter técnico no se debe solo a una cuestión de la localización de conocimientos, sino también de preservar el carácter simbólico general de los demás tribunales.

${ }^{38}$ Véase Joseph Goldstein, The Intelligible Constitution: The Supreme Court's Obligation To Maintain The Constitution As Something We The People Can Understand (1992). 
creencia no se mantiene como una cuestión de teoría democrática, sino como una práctica cultural de rito, mito y fe, en el centro de la cual nos encontramos con los jueces de la Corte Suprema.

Nuestros jueces no solo representan la nación como una sola comunidad sujeta al derecho. Su papel es performativo, no representativo. La Corte es el lugar de nuestra creencia en nosotros mismos como pueblo soberano. Escuchando a la Corte nos escuchamos a nosotros mismos. Este es el significado y el legado de Marbury. La Corte pronuncia las palabras del pueblo soberano solo mientras y en la medida que el pueblo crea que lo hace. La legitimidad de la voz judicial depende de la capacidad de la Corte para mantener esta creencia. Los jueces deben, en consecuencia, mantener un sentido de contacto con el pueblo: son hombres comunes y no una élite distinguida por una formación y un conocimiento esotérico ${ }^{39}$. Por supuesto, esto no quiere decir que pensamos que ellos pueden ser ignorantes jurídicamente. Pero hay una continuidad entre el jurado, el juez y el juez constitucional. Todos nos presentan a nosotros como una comunidad que se autogobierna.

En la lengua vernácula de la creencia común, nos encontramos con dos afirmaciones míticas conectadas: "cualquiera puede llegar a ser presidente" y cualquier persona tiene derecho a tomar sus quejas "hasta llegar a la Corte Suprema". Este sentido de autogobierno mediante el derecho se ve amenazado por el reconocimiento demasiado explícito de una ciencia jurídica. En efecto, las alegaciones de una ciencia jurídica en este país fueron profundamente desacreditados en la primera parte del siglo XX, cuando la Corte permitió que una profunda distancia surgiera entre su voz y la de la opinión popular ${ }^{40}$. La Corte, como dijo Alexander Bickel, "trabaja bajo la obligación de tener éxito", lo que quería decir que sus opiniones no solo deben ser fundadas, sino que deben ser aceptadas como tales por la nación ${ }^{41}$.

Para entender lo que está pasando aquí tenemos que pensar en los ritos que transforman una persona común y corriente en un sacerdote. En una época en que ya no se cree en el antiguo Dios de la Iglesia, podríamos decir que no puede haber una verdadera transformación de la persona. El sacerdote, somos muy conscientes, sigue siendo la misma persona, con los mismos intereses, deseos, e incluso pasiones. Podríamos decir esto porque sabemos que es verdad. Pero nosotros no lo decimos porque estamos dispuestos a suspender nuestra incredulidad. Entendemos que un universo simbólico del significado no es meramente un universo de intereses personales. El poder no existe como una capacidad individual de tomar ventaja de una posición social sino que el poder existe como un papel que se hace posible gracias a una cultura de creencias que

${ }^{39}$ Véase Frank I. Michelman, The Supreme Court 1985 Term - Foreword: Traces of Self Government, 100 Harv. L. Rev. 4 (1986).

${ }^{40}$ Véase Paul W. Kahn, Legitimacy and History: Self-Government in American Constitutional Theory 125-31 (1992) [de aquí en adelante Kahn, Legitimacy and History].

41 Alexander M. Bickel, The Least Dangerous Branch: The Supreme Court At The Bar Of Politics 239 (2d ed. 1986). 
es compartida por uno y los demás ${ }^{42}$. Ni sacerdote ni juez median entre el individuo y un sujeto trascendente. Ambos median entre el individuo y un orden simbólico que es igual de real que el lenguaje o la historia. Eso, sin embargo, no solo es suficientemente real sino que es la única realidad que hemos tenido.

El estado de derecho estadounidense no es ni política ni ciencia. Reconocer esto es el primer paso en dirección a la comprensión del derecho como un sistema simbólico propio. Al igual que esos sistemas, ofrece un ordenamiento completo del mundo. Desde dentro del derecho, podemos mirar hacia fuera a la ciencia y a la política -el derecho ofrece una comprensión de ambos. Pero lo hace sin colapsar en ninguno de los dos-. El constitucionalismo comparado, desde la perspectiva de un enfoque cultural, no debe colapsar la investigación sobre el estado de derecho en la ciencia o en la política. Todo está en juego, por lo tanto, en los supuestos iniciales de la investigación. Si queremos entender el significado de la revisión judicial, no podemos simplemente mirar a las doctrinas de los derechos que se producen por los tribunales, ni las maniobras políticas que tratan de determinar sus resultados. Tenemos que buscar su lugar en los rituales y mitos del derecho -el contenido de la fe en el gobierno del derecho-.

\section{Algunas divisiones iniciales}

Todo Estado moderno occidental se caracteriza a sí mismo como democrático y como sometido a la ley. Ningún Estado puede ignorar o desechar estos términos, pues ellos inciden directamente en la legitimidad de la comunidad política y de su forma de gobierno. Ambos remiten no tanto a un conjunto de prácticas bien definidas, sino que a una comprensión socialmente compartida del yo colectivo: el Estado debe lograr ser percibido por sus ciudadanos como democrático y como sujeto al Derecho. Aún así, ni el significado de estos términos, ni la relación que mantienen entre sí, es evidente. De hecho, ambos constituyen maneras de entender o caracterizar la totalidad de lo estatal desde un particular punto de vista. Un Estado democrático puede incluir instituciones que no sean democráticas, y puede constreñir el ámbito de decisiones que se puedan tomar democráticamente; pero ambos tipos de límites deben ellos mismos estar fundamentados en una comprensión adecuada de las condiciones requeridas por la legitimidad democrática. Los Estados democráticos no sitúan ningún aspecto de la vida social fuera del rango de preocupaciones de la ciudadanía democrática, incluso si la conclusión consista en excluir dicho ámbito del alcance inmediato de la política democrática.

Lo mismo ocurre con el estado de derecho. Un estado de derecho no deja espacio para un poder discrecional no sometido al imperio de la ley. Más bien, la discreción es un componente del derecho. Por ejemplo, el Presidente de Estados Unidos tiene una considerable discreción en materia de política exterior debido a que la Constitución le ha asignado tal rol. El estado de derecho no obedece a la división entre lo público y

\footnotetext{
${ }^{42}$ Por supuesto, todo poder puede ser objeto de abuso para perseguir fines personales.
} 
lo privado. La ley puede tener poco qué decir sobre los asuntos privados de la familia, pero lo que ello significa es que aquellos asuntos están protegidos por la ley. Esto nos queda claro cuando exista una desviación patológica de la norma. El moderno estado bienestarista puede intervenir significativamente en la familia cuando sea necesario. La familia también es un espacio regulado por el derecho ${ }^{43}$.

Desde la perspectiva del estado de derecho, todo lo que está fuera de él es "ilegal". Respecto de cualquier acción o propuesta realizada en el ámbito estatal es posible formular la siguiente pregunta: ¿es aquello legal? Siempre hay una respuesta afirmativa o negativa a dicha pregunta ${ }^{44}$. De manera similar, respecto de cualquier objeto o espacio, podemos preguntarnos, ¿quién es su dueño?, y respecto de cualquier sujeto podemos preguntarnos, ¿es un ciudadano? Un estado que permite a la ley gobernar tan solo algunos de sus aspectos resultaría no ser un estado de derecho. Si no hay un afuera, entonces es un error pensar en el derecho como algo distinguido por algún rasgo o característica, un enfoque característico de la filosofía analítica. El estado de derecho es un orden simbólico constitutivo de toda una concepción del mundo. Es tan comprehensivo como la ciencia, la religión o la economía. No hay fenómeno que carezca de explicación científica, de lugar en el plan divino, o de valuación económica. Tampoco existe nada que sea insensible al derecho. Explorar la cultura del imperio de la ley es describir la manera en que un mundo de significado jurídico es creado y mantenido.

La creación no comienza con una Constitución. La relación entre Constitución y estado de derecho no es una relación de causalidad, como si el ordenamiento jurídico emanara como un todo de la Constitución. Más bien es al revés. Porque creemos en el estado de derecho, hacemos que sea posible la Constitución. Los estados que no creen en el imperio de la ley pueden tener, formalmente, una Constitución, pero esas constituciones no desempeñan la función jurídica que se espera de ellas en Occidente. De la misma manera, antes que nos confrontemos con el texto, necesitamos interrogarnos sobre las posibilidades que dicho texto puede satisfacer. Aquellas posibilidades están establecidas en la estructura de creencias que se atribuyen a la idea misma del estado de derecho dentro de una comunidad.

Los académicos que se dedican al comparativismo constitucional, así como los observadores no especializados, suelen hacer una distinción inicial entre Estados con o sin una Constitución escrita. Posteriormente, harán una distinción ulterior entre sistemas de representación: parlamentaristas o presidencialistas, federalistas o centralistas. Finalmente, es probable que diferencien entre sistemas constitucionales de acuerdo con la existencia y características de la revisión judicial: abstracta o concreta, entregada a una Corte especializada o a la judicatura ordinaria. Tras haber delineado grandes categorías estructurales, llevarán a cabo un análisis comparativo de los derechos constitucionales: sociales y económicos, políticos y civiles. Quiero sugerir una tipología distinta: entre

43 Véase Jill Elaine Hasday, Parenthood Divided: A Legal History of the Bifurcated Law of Parental Relations, 90 Geo. L.J. 299 (2002).

${ }^{44}$ Que el orden internacional no haya tenido esta cualidad ha sido una de las razones para el tradicional escepticismo en cuanto a que el derecho internacional sea derecho. 
regímenes constitucionales que pretenden sustentarse en una voluntad soberana y aquellos que reposan sobre una pretensión de racionalidad. Solo cuando confrontemos esta distinción podremos comenzar a dar respuesta a la siguiente pregunta: ¿cuál es la estructura de creencias que caracteriza a la judicatura encargada de realizar la revisión judicial?

En Occidente, nunca estamos demasiado lejos de esta doble fuente de autoridad: la razón y la voluntad. La ley como voluntad del soberano expresa nuestra idea más antigua del origen del derecho; la ley como expresión de la razón es nuestra más antigua fuente de la crítica del derecho. Incluso un Dios creador está sujeto a la crítica de la razón; ese es el rompecabezas para el cual la historia de las teodiceas occidentales debía ser la respuesta ${ }^{45}$. La voluntad divina puede ser la fuente del derecho, pero la voluntad divina no puede ser irracional. Si esa voluntad se nos presenta como arbitraria y caprichosa, debe haber un problema en la comprensión humana del plan divino. La distinción se refleja en la monarquía tradicional europea. A partir de ideas acerca de la voluntad y la presencia divinas, el monarca en cuanto soberano era concebido como el cuerpo místico del Estado ${ }^{46}$. La ley expresa la voluntad de este soberano, lo que no es lo mismo que la voluntad singular del individuo que circunstancialmente se desempeña como rey. La transformación del individuo en el soberano es un proceso ritual independiente de la profundidad de su capacidad para juzgar o gobernar. La ascensión al trono es un asunto de legitimidad; un usurpador usualmente es caracterizado como “ilegítimo”. La legitimidad del poder, sin embargo, no es una respuesta al problema del gobierno justo. Incluso el poder legítimo puede servir para el abuso. La respuesta a ese problema consiste en el gobierno de acuerdo con la razón.

Exactamente el mismo razonamiento se encuentra en un Estado democrático. Un gobierno puede llegar al poder mediante una victoria electoral. La legitimidad electoral, sin embargo, no es el único criterio normativo que empleamos al evaluar un gobierno y su derecho. Poca gente fuera de Serbia estaba contenta cuando Milosevic fue electo. De hecho, incluso dentro de Serbia, los kosovares y muchos otros tenían buenas razones para temer a su elección. Un gobierno puede abusar de su legítimo poder al emplearlo para perseguir intereses faccionales en lugar de servir al bienestar público. Rousseau advierte que incluso si la facción expresa la voluntad de todos, aun así puede ser sometida a la crítica de la razón por no lograr servir al bien colectivo ${ }^{47}$. Platón defendió el mismo punto en los orígenes de la filosofía occidental: la búsqueda del interés sin conocimiento del bien puede igualmente conducir al fracaso moral y político como al triunfo ${ }^{48}$. No solo las autocracias pueden autodestruirse; también puede lograrlo una democracia.

En la tradición liberal, el único estándar con que evaluar el bienestar colectivo es el discurso racional. Por supuesto, incluso entre liberales no existe una única dirección identificable como el camino del "discurso de la razón”. La apelación a la razón no nos

\footnotetext{
45 Véase Susan Neiman, Evil In Modern Thought: An Alternative History Of Philosophy (2002).

46 Véase Ernst H. Kantorowicz, The King's Two Bodies: A Study In Mediaeval Political Theology (1957).

${ }^{47}$ Véase Jean-Jacques Rousseau, The Social Contract 72-74 (Maurice Cranston ed., Penguin 1968) (1762).

${ }^{48}$ Véase Platón, Gorgias 466b-468e (G.P. Goold ed., 1961).
} 
dice por sí misma si debiéramos ser contractualistas rawlsianos o utilitaristas; o qué tan amplio debiera ser nuestro reconocimiento de lo que constituye algo útil. Sí nos dice, sin embargo, que un argumento que simplemente aboga por el interés de una facción o de un individuo no califica por sí mismo como una razón pública para la acción colectiva.

Cada sociedad moderna ha de mantener un debate serio respecto del carácter de la justicia y el bienestar colectivo. Ese debate está necesariamente vinculado al derecho, no solo porque el derecho sea coercitivo y la coerción deba estar justificada en una sociedad liberal; también, porque el derecho ofrece una imagen de nosotros mismos y de nuestros valores públicos. El acercamiento liberal al constitucionalismo y a las cortes constitucionales consiste en pensar en la revisión judicial como el lugar del discurso autoritativo sobre la razón pública. Esta es una posición que fácilmente acomoda, por ejemplo, a la ética discursiva de Habermas o a la idea de la autopoiesis del derecho de Luhmann ${ }^{49}$. Vemos este movimiento hacia el discurso de la razón en la Corte Suprema de Estados Unidos, cuando la Corte invoca la necesidad de un "juicio sólido" para determinar qué derechos fundamentales están "implícitos en un concepto ordenado de libertad" 50 .

El constitucionalismo liberal tiende a detenerse en este punto, al ver la necesidad de elegir entre el faccionalismo y el bienestar colectivo. Esta decisión es negociada exitosamente cuando el derecho se transforma en la expresión internalizada de la razón en el ámbito del orden público. Pero hay una reacción igual, si bien opuesta, a la percepción del riesgo del surgimiento de faccionalismos o intereses personales dentro de los mecanismos institucionalizados de gobierno. Si describimos el giro hacia la razón como una forma de apelación a la justicia en orden a determinar qué exige el bienestar colectivo, podemos describir el giro hacia la voluntad soberana como un giro hacia la legitimidad. Precisamente debido a que la justicia es un concepto controversial, la apelación a la justicia no puede por sí misma suprimir la normatividad alternativa de la legitimidad, y viceversa.

Esta concepción de la legitimidad no se agota en los mecanismos de la política electoral. La política constitucional no es simplemente la política electoral habitual. Más bien, la política constitucional invoca una identificación con el soberano popular transhistórico. Un rey que no fuese percibido como la encarnación del cuerpo místico del Estado fracasaba en esta dimensión de la legitimidad incluso si accedía válidamente al trono. Un líder electo que es visto como el representante de intereses partidistas, no como el representante de la totalidad de la nación, fracasa igualmente en la dimensión de la política constitucional. Los líderes deben hablar en la voz del soberano popular para que los ciudadanos puedan verse a sí mismos como participantes en un proyecto político que pueda pedirles su adhesión individual. Ese proyecto establece el vínculo que el ciudadano siente entre su yo y la narrativa colectiva, lo que, a su vez, da sustento

${ }^{49}$ Véase Habermas On Law And Democracy: Critical Exchanges (Michel Rosenfeld \& Andrew Arato eds., 1998); Niklas Luhmann, The Unity of the Legal System, en Autopoietic Law: A New Approach To Law And Society (Gunther Teubner ed., 1987).

50 Véase Planned Parenthood v. Casey, 505 U.S. 833, 951 (1992); Palko v. Connecticut, 302 U.S. 319,325 (1937). 
a la producción de una historia entendida como única y a un destino compartido. Los ciudadanos mantienen no solo una relación racional con sus conciudadanos y con el Estado, sino también una relación identitaria. Se entienden a sí mismos como participantes mutuos en un proyecto histórico singular y están dispuestos a sacrificarse a sí mismos para asegurar el éxito de dicho proyecto.

Esta es la dimensión del liderazgo político que Weber identifica con el carisma ${ }^{51}$. Ello, sin embargo, es personalizar demasiado. Más importante aún, es no comprender la dirección hacia la cual debemos mirar en búsqueda de expresiones de soberanía popular, pues con seguridad tal conceptualización nos hará nuestra mirada hacia la política electoral en lugar del derecho. En los Estados Unidos, la fuente más importante de la voluntad transtemporal del soberano popular se encuentra en la Corte Suprema. Difícilmente podría decirse que sus jueces sean líderes políticos carismáticos; sin embargo, el discurso de la Corte está en gran medida inspirado en la retórica política de la legitimidad. Esta es la fuerza que anima el giro en el discurso constitucional norteamericano hacia los redactores de la Constitución, su intención original, y el texto en cuanto artefacto histórico. Es la fuente de la resistencia judicial al discurso del derecho natural, la ciencia jurídica, y pretensiones fundadas en la universalidad de los derechos.

La sentencia Marbury fue fundamental en el desarrollo de esta tradición de aucomprensión judicial. Marshall identifica la voz de la Corte con la voz del soberano popular. Si la Constitución es expresión de la soberanía popular y el rol de la Corte es "decir lo que el derecho es”, entonces el dictamen de la Corte es la sentencia del pueblo. Aquí mismo encontramos una reflexión relativa a la voluntad soberana. Esta asimilación implica, asimismo, que el Presidente y el Congreso representan tan solo la opinión popular, la que siempre está vinculada a las circunstancias presentes. La opinión popular es cambiante, mientras que el dictamen del pueblo es permanente. Es, asimismo, una posesión permanente de la Corte. El éxito de Marbury consiste en la fuerza de la creencia de que la soberanía popular y el estado de derecho son una misma cosa; el estado constitucional de derecho es la expresión del gobierno de la voluntad popular. La construcción cultural de la Corte es la elaboración de esta pretensión fundamental de que aquí encontramos la fuente sagrada de la nación misma.

Tal como el ideal de un discurso racional no especifica los contenidos de la razón, el ideal de un discurso de la soberanía no especifica el carácter de la voluntad nacional. Encontramos dos posiciones primordiales al respecto en la política moderna. Una identifica a una nación prepolítica como el sujeto de la voluntad; el otro, identifica la nación con una comunidad de ciudadanos, comprometidos unos con otros por medio de las instituciones y las leyes del Estado. Este debate entre el nacionalismo étnico y el nacionalismo cívico ha representado una pugna en torno al alma misma del Estado-nación moderno ${ }^{52}$. En la época posterior a la Guerra Fría, la disputa literalmente ha derivado

${ }^{51}$ Véase Max Weber, The Theory Of Social And Economic Organization 358-73 (A.M. Henderson \& Talcott Parsons trans., Oxford Univ. Press 1947).

52 Véase Michael Ignatieff, Blood And Belonging: Journeys Into The New Nationalism 243 (1993). 
en una batalla, a medida que los movimientos nacionalistas étnicos han resistido las normas del nacionalismo cívico compartidas por los dos imperios multiétnicos de la Guerra Fría. Yugoslavia fracasó como un Estado cuando sus ciudadanos dejaron de verse a sí mismos como participantes en un proyecto histórico compartido de construcción y mantención de Estado que definiese quiénes eran. La experiencia yugoslava es tan amenazante simbólicamente para Europa debido a su latente tradición de nacionalismo étnico, que mina el proyecto del nacionalismo cívico representado no solo por la Unión Europea sino por el emergente reconocimiento del carácter multicultural de los Estados europeos mismos. La misma batalla está en curso a medida que se debate entre sus dos fuentes de legitimidad: el ser tanto un Estado judío como un Estado democrático y liberal.

Esta distinción entre razón y voluntad marca una fundamental diferencia al responder la pregunta sobre qué es lo que una Constitución hace. Desde un punto de vista, la Constitución es la expresión de la razón dentro de lo que sería, de otra forma, un continuo conflicto de intereses entre los individuos, partidos e instituciones que constituyen el Estado. El problema que enfrenta no es el de la construcción de una nación, sino que el de la organización justa de los intereses y los grupos de interés. Su ambición no es el constituir uno a partir de muchos, sino que el imponer orden en medio del desorden. El acto fundacional no es análogo a la creación divina del mundo mediante la palabra, sino más bien un tipo de investigación rawlsiana respecto de la razonabilidad de la estructuración de un proyecto político común.

El carácter distintivo del estudio occidental del derecho es la creencia en la capacidad del derecho de internalizar los principios de la razón. Esta primera concepción del constitucionalismo identifica dichos principios con la Constitución, sea que ella esté escrita o no. De hecho, la ausencia de un texto constitucional no es significativa desde esta perspectiva, pues sostener que algo es inconstitucional equivale a decir que no es razonable. El rol de una Corte constitucional es mantener la razonabilidad de la polis subordinando la política, siempre expresión de intereses, al derecho.

La identidad política no está en juego en esta concepción del constitucionalismo y del rol de los jueces ${ }^{53}$. Ella nos interroga, por ejemplo, acerca de las condiciones necesarias de un orden político justo; a manera de respuesta, ofrecemos una doctrina pertinente a los derechos. De la misma manera, nos pregunta cuál es el mejor método de organizar la actividad política, y respondemos con doctrinas concernientes a la separación de poderes, sobre el gobierno parlamentario, o de la revisión de constitucionalidad. Desde esta perspectiva, las constituciones son experimentales, no existenciales. Están sujetas a normatividades exteriores - por ejemplo, a la justicia o a la eficiencia- en lugar de ser entendidas como constitutivas del significado de lo político. Podemos identificar un residuo de ello dentro del derecho constitucional norteamericano en su continuo apego al estándar de mínima racionalidad. La Corte jamás podría sostener que el ordenamiento

53 Esto requiere algunos matices, pues el compromiso con un liberalismo de la razón puede ser también un compromiso con algún tipo de ciudadanía, por ejemplo, con la ciudadanía liberal. Véase el texto en la nota 72. Este compromiso puede que se vea cualificado por la comprensión de que lo que está en juego no es el liberalismo como un todo, sino tan solo su expresión política. 
jurídico sea indiferente a su propia razonabilidad. Sin embargo, lo que es un estándar débil y políticamente inefectivo aquí puede ser en otro lugar la fuente primaria de la revisión de constitucionalidad.

Por ejemplo, la revisión judicial en la Corte Suprema de Israel consiste en un incesante recurso a la revisión de proporcionalidad ${ }^{54}$. La proporcionalidad no es nada más que la expresión contemporánea de la razonabilidad. Esto es lo que la Corte israelí promete: que garantizará que las acciones tomadas por el Estado satisfagan un examen de razonabilidad. La razonabilidad requiere, en primer lugar, una especificación del derecho en discusión -determinación que es, en sí misma, un producto de la ciencia jurídica liberal-y, en segundo lugar, la evaluación de dicho derecho a la luz del interés estatal en la acción examinada. La Corte israelí no es la única que encuentra su voz en el intento por expresar las demandas de la razón por medio de un juicio que abarque todos los aspectos relevantes. La revisión de proporcionalidad es central, por ejemplo, para la jurisprudencia de la Corte Suprema de Canadá 55 .

La revisión de proporcionalidad es a menudo criticada como un juicio práctico que carece de fundamentos jurídicos y que involucra a los tribunales en la formulación de políticas públicas ${ }^{56}$. Esta crítica, sin embargo, no logra comprender la genealogía de la revisión de proporcionalidad, que se sitúa en la creencia de que el estado de derecho constituye la internalización de la razón misma como ideal regulativo del ordenamiento político. La proporcionalidad es la forma que la razón toma cuando ya no existe fe en el formalismo - por ejemplo, cuando la razón deba ser sensible a las circunstancias- y cuando la creencia en un orden coherente que subyace a los intereses en conflicto pierde crédito. El descrédito del formalismo, en efecto, comprende a la totalidad de las ciencias sociales, las cuales una tras otra llaman a la evaluación de intereses particulares dentro de circunstancias particulares. El modelo del razonamiento judicial pasa a ser el de un circunscrito juicio de "equidad", una manifestación de la razón ya descrita por Aristóteles $^{57}$. Esto no significa que ya no exista espacio para la elaboración de juicios fundados en principios - de hecho, la identificación de derechos continúa apelando a tales principios-, sino que esos principios no se pueden aplicar independientemente de un juicio contextualizado que tome en consideración los intereses en disputa.

En la medida en que subsista la creencia en una ciencia jurídica formal, el juicio razonado de las cortes seguirá pareciéndonos distinto del razonamiento holístico de los órganos políticos. Cuando la razonabilidad reemplaza a la ciencia, sin embargo, el trabajo de las cortes no se diferencia mucho de los frutos de la prudencia. Puede ser que la prudencia sea una virtud política, pero ¿por qué habría de ser la norma constitucional

${ }^{54}$ Véase Aharon Barak, Foreword: A Judge on Judging: The Role of a Supreme Court in a Democracy, 116 Harv. L. Rev. 16 (2002).

${ }^{55}$ Véase, por ejemplo, R. v. Edwards Books \& Art Ltd., [1986] 2 S.C.R. 713, 768; R. v. Oakes, [1986] 1 S.C.R. 103, 135-40. R. v. Edwards Books \& Art Ltd., [1986] 2 S.C.R. 713,768.

${ }^{56}$ Véase, por ejemplo, Richard Fallon, Foreword: Implementing the Constitution, 111 Harv. L. Rev. 54 , 79-80 (1997); Antonin Scalia, The Rule of Law as a Law of Rules, 56 U. Chi. L. Rev. 1175, 1179-81 (1989).

57 Aristotle,The Nicomachean Ethics, Libro V, capítulo 10 (1137b 19-24). 
a la cual todas las demás virtudes políticas deban ajustarse? Al fin y al cabo, la idea de un juez de lo que es prudente probablemente será evaluada a partir de consideraciones políticas: ¿está la comunidad política mejor, tomando en cuenta todos los factores relevantes, con jueces que realicen un juicio de segundo orden sobre la razonabilidad de lo resuelto por otras autoridades? Esta pregunta será respondida en cierta medida mediante un juicio sobre las políticas que resulten de ello; el tipo de análisis que podría hacer un cientista social. Pero también será respondida en parte por la continua apelación al ideal occidental del derecho como la internalización de la razón, aun cuando las formas de la razón cambien.

Si nos movemos desde las cortes nacionales a las transnacionales, la apelación a la razón se vuelve más enérgica precisamente porque desaparece la contraparte de la voluntad soberana. Está presente, por supuesto, el formalismo del texto del tratado respectivo, el que puede ser entendido como una expresión de voluntades nacionales expresadas en la forma de su ratificación. Pero los tribunales internacionales contemporáneos no son órganos arbitrales; sus textos fundacionales dan voz a ideales y principios que requieren interpretación, no simplemente la aplicación formal de dicho texto. La expansión de la Corte Europea de Justicia hacia el dominio de los derechos humanos fue un poderoso ejemplo de la independencia de la razón respecto de los textos ${ }^{58}$. Esa corte, también, concibe la razón como razonabilidad. Esto está plenamente en concordancia con el ideal del desarrollo de Europa, que no consiste en una movilización de una voluntad transnacional europea, sino en el desarrollo de un razonable curso de acción. Las normas que constituyen a Europa son burocráticas, no democráticas. El estándar de la razón dentro de esta administración es precisamente el ideal de la razonabilidad prudencial. En consecuencia, el poder de la Corte europea está intrínsecamente vinculado a su capacidad de expresarse como la voz de la razonabilidad, que mantiene a raya las patologías de la administración, por un lado, y del autointerés nacional, por el otro.

La razonabilidad y la proporcionalidad pueden dominar el discurso judicial en gran parte de Europa, pero sería un error ver ahí el único modelo para el futuro de la revisión judicial. Difícilmente se puede decir que la revisión de proporcionalidad esté ausente del discurso judicial norteamericano, pero siempre es vista aquí con cierto escepticismo debido a la percepción de que comparte demasiadas características con un juicio de carácter político ${ }^{59}$. El punto más profundo aquí es que la fuente del poder de la Corte norteamericana se encuentra en la dirección de la voluntad, no de la razón. Esta Corte está preocupada primordialmente de la legitimidad, no de la justicia.

En un Estado en el que la ciudadanía es entendida como un asunto de identidad cívica, no étnica, la Constitución representa quizás el más importante punto de reificación del grupo. La Constitución es entendida como la autoexpresión de la soberanía popular. Es un producto de su voluntad, y en consecuencia una objetificación de la idea

58 Véase J.H.H. Weiler, The Transformation of Europe, 100 Yale L.J. 2403, 2417 (1991).

${ }^{59}$ Véase T. Alexander Aleinikoff, Constitutional Law in the Age of Balancing, 96 Yale L.J. 943 (1987); Paul W. Kahn, The Court, the Community and the Judicial Balance: The Jurisprudence of Justice Powell, 97 Yale L.J. 1 (1987). 
fundante de la nación como una comunidad que se constituye a sí misma. Este es el caso en Estados Unidos, donde cada afirmación de lealtad política -los juramentos que deben rendir las autoridades al momento de su investidura, o los extranjeros en el momento de su adquisición de la nacionalidad, por ejemplo- tiene a la Constitución como su destinatario $^{60}$. La Constitución es la voluntad soberana en cuanto objeto que subiste en el mundo. La voluntad política es poder, y un poder no expresado no es ningún poder. En este sentido, la Constitución es políticamente análoga a la Biblia. La Biblia no es tan solo una expresión de la voluntad divina; es el punto en el que dicha voluntad divina se manifiesta y se constituye así como un poder.

Aún así, observar esta función de las constituciones no equivale a especificar qué relación mantendrán las instituciones con ellas. Los franceses ven su Revolución en términos muy similares a los que emplean los norteamericanos: la movilización de la soberanía popular como un acto de voluntad. Ellos, también, se identifican con una tradición revolucionaria de nacionalismo cívico. Pero los tribunales franceses no emergieron de la Revolución con el poder de hablar en nombre del soberano popular. El sitio de dicha voz fue, en cambio, la Asamblea Nacional francesa ${ }^{61}$. Al comparar las experiencias judiciales francesa y norteamericana surge la pregunta de qué condiciones habilitan a un tribunal a hablar en nombre del soberano popular. No existe una respuesta abstracta a dicha pregunta. Sabemos que es posible debido a que la Corte norteamericana de hecho lo logró.

El punto más importante de Marbury es la pretensión de la Corte que habla en nombre del soberano popular. Hacia el final de esta sentencia, hemos de creer que el veredicto de la Corte es el veredicto del pueblo. Lo correcto no es decir que la autoridad de la Corte deriva del pueblo; más bien, la decisión de la Corte equivale literalmente a la autoridad del pueblo. Marbury comienza como una continuación de la elección de 1800; una contienda entre federalistas y republicanos en torno a la representación. La Corte triunfa en esta contienda, al menos en el largo plazo, al formular una pretensión situada más allá de la representación. La voz de la Corte es la sagrada voz del pueblo mismo ${ }^{62}$.

Por supuesto, a la Corte le interesa evitar que parezca que el pueblo soberano habla de manera irracional. Por ello, no puede ignorar el ideal de la internalización de las normas de la razón dentro del ordenamiento jurídico. Sin embargo, en el constitucionalismo norteamericano la voluntad precede a la razón, y la legitimidad precede a la justicia. El pueblo soberano primero debe crearse a sí mismo por medio de su propia habla. Esto representa un acto de la voluntad. Dios habló y hubo algo en lugar de nada; el pueblo habló y hubo algo nuevo en el mundo. Las técnicas de la decisión judicial no derivan primariamente de las necesidades de la razón, sino que de aquellas de la voluntad. Todos

${ }^{60}$ Esta tradición de patriotismo dirigida a la Constitución es lo que hizo el nuevo discurso de la seguridad de la "patria" tan disonante para algunos.

${ }^{61}$ Acerca del desarrollo de la revisión de constitucionalidad en la Francia de postguerra, véase Stone, supra nota 27.

${ }^{62}$ Para una exploración de las técnicas retóricas y conceptuales mediante las cuales la Corte logra esto, véase Kahn, Reign of Law, supra nota 1, 102-174. 
nuestros veredictos constitucionales comienzan con el texto y de ahí se dirigen a la historia del mismo. Incluso aquellos académicos y abogados que desean ir más allá, deben comenzar con el texto y su historia. Esto no se debe a que estas fuentes nos ofrezcan respuestas claras, o a que eliminen el debate interpretativo; más bien, se debe a que es mediante el texto mismo que se mantiene la identidad entre la voz judicial y la voz del soberano popular. La Corte es, literalmente, todos nosotros; mantiene aquella fe en el cuerpo místico del Estado, que no es sino el soberano popular.

El problema fundamental del constitucionalismo democrático consiste en negociar la relación entre la razón y la voluntad. No se trata de identificar particulares espacios institucionales o principios específicos, como podría pensarse desde dentro de una práctica cultural que incluye voces en disputa e instituciones que formulan argumentos de ambos tipos. Desde la perspectiva del análisis cultural, sin embargo, la razón y la voluntad no son regímenes institucionales ni principios objetivos. Mucho de lo que ha sido considerado como un avance razonable ha resultado ser bastante poco razonable; desde la alquimia al derecho divino, pasando por la ciencia newtoniana en un mundo de quarks. La razón opera en el derecho no en la forma de los ardides de la razón de Hegel, sino como un conjunto de ideas que las Cortes y otros consideran apropiadas en momentos específicos. Asimismo, no existe una medida que no requiera de contextualización con la que podamos evaluar la veracidad de una pretensión de expresar la voluntad del soberano popular. La diferencia entre un golpe y una revolución se encuentra en la percepción de la ausencia o presencia del soberano popular; es un asunto de creencias, no de metafísica. El soberano popular está presente cuando existe una creencia en su presencia. Cada revolución fracasada es vista, en retrospectiva, como carente del respaldo del soberano popular. Pero incluso esfuerzos derrotados pueden ser recuperados cuando la historia es reescrita por un posterior esfuerzo revolucionario triunfante ${ }^{63}$. La negociación de la relación entre razón y voluntad se asemeja más bien a una negociación del espacio entre dos dioses - el Padre y el Hijo- que a la negociación de un contrato entre partes cuyos intereses divergen. Es una tarea hermenéutica, constreñida por las posibilidades ya existentes dentro de una cultura.

Tenemos, en consecuencia, dos conjuntos de distinciones que pueden servir para bosquejar el carácter del discurso constitucional o, más directamente, la voz de una corte encargada de la revisión judicial. En primer lugar, está la distinción entre razón y voluntad o entre justicia y legitimidad. Cada una de estas formas de discurso tiende hacia una perspectiva totalizante. Por ello, el discurso de la justicia fácilmente ignora la importancia de las fronteras nacionales. Se mueve naturalmente hacia normas universales; aspira a instituciones de gobierno internacionales. Una voz judicial que se sustenta fundamentalmente en un discurso de la razón se desplazará fácilmente desde lo particular a lo comparativo, y de ahí a lo universal. Este es el patrón de razonamiento que se encuentra detrás de la emergencia de una sólida Corte Europea de Justicia en

63 Considérese las revueltas europeas de 1848 o el fenómeno inverso al comprender a los Estados Confederados o a los Bolcheviques. 
una relación jerárquica con los tribunales constitucionales domésticos ${ }^{64}$. Asimismo, el discurso de la legitimidad puede fácilmente marginalizar las aspiraciones universalistas. La jurisprudencia constitucional norteamericana nos entrega numerosos ejemplos de este fenómeno, incluyendo la temprana afirmación del Juez Iredell criticando cualquier uso judicial de teorías de la justicia abstractas:

Las ideas de la justicia natural no están reguladas por ningún estándar fijo: los hombres más inteligentes y más honestos han diferido en la materia; y todo lo que la Corte puede adecuadamente decir... es que la Legislatura .. ha promulgado una ley que, en opinión de la mayoría de este tribunal, es inconsistente con los principios abstractos de la justicia natural ${ }^{65}$.

La resistencia judicial norteamericana a los argumentos provenientes del derecho internacional y comparado encuentran su fuente en una idea del excepcionalismo norteamericano que se sustenta no únicamente en el poder norteamericano, sino más bien en una energética concepción de la soberanía popular como la fuente del estado de derecho ${ }^{66}$. Quienes cuestionan el excepcionalismo jurídico norteamericano apelan, demasiado a menudo, a un discurso de la razón que simplemente no logra sintonizar con la norma fundamental del estado de derecho norteamericano.

En segundo lugar, dentro de cada una de estas categorías se puede hacer una distinción adicional. Dentro del discurso de la razón, podemos distinguir entre aquellas cortes constitucionales que buscan servir a una autónoma "ciencia jurídica”, y aquellas que entienden su rol como mediadores entre el derecho y la razón en general. En el pensamiento iusfilosófico norteamericano, esta distinción está marcada por Langdell en un extremo y Dworkin, o los cultores del análisis económico del derecho, en el otro. El razonamiento constitucional de la Corte Suprema, inspirado por la tradición del common law, en una sentencia como Lochner ${ }^{67}$, difiere considerablemente del razonamiento ecléctico e inspirado en las ciencias sociales de Brown ${ }^{68}$. En las cortes europeas emerge un conflicto similar a medida que ellas se desplazan desde el formalismo tradicional característico de la ciencia jurídica continental hacia un modelo de la razonabilidad como revisión de proporcionalidad ${ }^{69}$. Dentro del discurso de la legitimidad podemos distinguir entre normas del nacionalismo étnico y cívico. La exploración del rol del nacionalismo étnico en el siglo XIX y el temprano siglo XX es un campo floreciente en

${ }^{64}$ Véase los casos Solange alemanes como expresión de resistencia y colapso: Decisión de 22 de octubre de 1986, BVerfGE 73, 339; Decisión de 29 de mayo de 1974, BVerfGE 37, 271.

${ }^{65}$ Calder v. Bull, 3 U.S. (3 Dall.) 385, 398-99 (1798) (Iredell, J.).

66 Véase, por ejemplo, Printz v. United States, 521 U.S. 898, 921 n.1l (1997).

${ }^{67}$ Lochner v. New York, 198 U.S. 45 (1905).

${ }^{68}$ Brown v. Bd. of Educ., 347 U.S. 483 (1954).

${ }^{69}$ Respecto de la creciente importancia de la revisión de proporcionalidad, véase Stone Sweet, supra nota 12, 97-99, 114-124. 
el estudio del derecho ${ }^{70}$. La experiencia de los tribunales europeos con el nacionalismo étnico es un recordatorio de que no podemos esperar que los tribunales nos salven de nosotros mismos ${ }^{71}$.

Si bien toda Constitución moderna debe negociar esta relación entre razón y voluntad, no toda judicatura lo hará en la misma manera. Si imaginamos un único eje en el cual se encuentren la razón en un extremo y la voluntad en el otro, podremos distinguir entre culturas constitucionales observando la dirección en la que se suelen situar. Un importante punto en el cual podemos hacer esta observación ocurre cuando un tribunal constitucional habla: ¿lo hace recurriendo a la voz de la soberanía popular, o invocando el nombre de la razón? El eje sugiere que la voz que emplearán no será necesariamente lo uno o lo otro. No hay exigencia que obligue a las cortes a elegir una alternativa en desmedro de la otra: ellas pueden emplear distintas voces en distintas circunstancias.

Cómo y dónde un tribunal constitucional se sitúa dentro de estas posibilidades es algo que depende tanto de la experiencia judicial como de creencias abstractas acerca de un orden constitucional. La experiencia judicial no es independiente del contexto más general de la experiencia política; particularmente, de la experiencia de la victoria y la derrota. Las normas constitucionales pueden provenir del exterior de la comunidad política: ellas pueden haber sido impuestas como consecuencia de derrotas políticas o de la intervención extranjera. En estas circunstancias, es improbable que el estado de derecho refleje el ideal cultural de la voluntad soberana. La emergencia de un constitucionalismo de la razón en Europa ciertamente refleja la desastrosa experiencia vigésimosecular de la política de la voluntad soberana. La soberanía popular norteamericana, por el otro lado, apela a una narrativa victoriosa que cuenta con 200 años tras de sí.

Pocas veces existe tan solo una única historia qué contar respecto de la relación entre razón y voluntad dentro de la filosofía constitucional: ambas fuentes están profundamente entrelazadas dentro del sistema de creencias occidental. La Corte de Estados Unidos, por ejemplo, aspiró a encarnar los ideales de la ciencia jurídica hacia fines del siglo XIX y comienzos del siglo $\mathrm{XX}^{72}$. Esta era una época de fe en el progreso nacional, pero también una época que vivía todavía bajo la sombra del "fracaso" del diseño constitucional original durante la Guerra Civil. En esta época, la ciencia del derecho constitucional tenía un distintivo sabor a darwinismo social; pero sería un error creer que esto era meramente una expresión de las creencias personales de los jueces. Ni siquiera una ciencia jurídica autónoma puede fundarse en ideas sobre la razón que sean incompatibles con "las mejores” teorías políticas de la justicia disponibles, así como tampoco podría la ciencia jurídica insistir en que el mundo es plano una vez que la mejor descripción existente es que el mundo es redondo. Aquella Corte no podía evitar el darwinismo social, tal como

${ }^{70}$ Véase, por ejemplo, Ian F. Haney Lopez, White By Law: The Legal Construction Of Race (1996); Efren Rivera Ramos, The Legal Construction Of Identity: The Judicial And Social Legacy Of American Colonialism In Puerto Rico (2001).

71 Véase, por ejemplo, Ingo Muller, Hitler's Justice: The Courts Of The Third Reich (Deborah Lucas Schneider trans., 1991).

${ }^{72}$ Véase Kahn, Legitimacy And History, supra nota 40, 108-17. 
la Corte de hoy no puede dejar de recurrir a ideales de justicia que presentan una cierta similitud con las teorías de John Rawls o Jurgen Habermas. No es una coincidencia que los derechos comunicativos y expresivos dominen gran parte de la filosofía constitucional contemporánea. En la experiencia norteamericana, sin embargo, esta apelación a la ciencia del derecho constitucional quedó desacreditada debido al enfrentamiento entre la Corte y el New Deal. El triunfo de Roosevelt nos legó una duradera caracterización de la ciencia jurídica como sinsentido trascendental ${ }^{73}$.

Si desplazamos nuestra atención desde los Estados Unidos del siglo XX hacia la Europa de postguerra, vemos una diferente experiencia constitucional, que comienza con el repudio de una política de la voluntad soberana. La revisión de constitucionalidad comienza con un modelo kelseniano. Kelsen es más cientista social que jurista, pues sitúa la razón fuera del derecho ${ }^{74}$. Kelsen cuestiona la constitucionalización de derechos, pues esto invita a los tribunales a utilizar argumentos extraídos directamente desde la razón dentro del derecho. En lugar de ello, Kelsen nos ofrece una teoría agenteprincipal de la autoridad constitucional, que reposa en la creencia en el positivismo jurídico: una filosofía jurídica desprovista de contacto con la vibrante política de la soberanía popular. Sin embargo, la historia de los tribunales constitucionales europeos nos habla del desplazamiento de estos hacia la dimensión de la razón. Los tribunales constitucionales europeos se apropiaron del lenguaje de los derechos, pilar fundamental de la jurisprudencia de la razón. Estos tribunales asumieron un rol positivo, ya no solo negativo, empleando el juicio situado de la razón en la forma de la proporcionalidad. Son los conductores del desarrollo de un orden jurídico transnacional de la razonabilidad. $\mathrm{Y}$ este discurso ha sido una parte importante del proyecto de establecer una identidad liberal para la ciudadanía europea.

\section{CONCLUSIÓN}

Puedo resumir gran parte de lo que he sostenido revirtiendo la dirección, y preguntando qué es lo que el constitucionalismo no es. No es una estructura política que protege los intereses de una facción a costa de otra. Cuando las estructuras constitucionales que nos ha legado el pasado asumen esta apariencia, están satisfechas las condiciones conceptuales para una revolución, más allá de si las condiciones materiales para una revolución exitosa estén presentes. Cada revolución contiene un relato pertinente al abuso de poder en beneficio de los intereses de un individuo o un grupo, incluso de una clase. Ya que cada comunidad política está marcada por la desigualdad, el peso de los privilegiados es siempre convencer a la población que dicha desigualdad de hecho satisface a sus

${ }^{73}$ Felix S. Cohen, Transcendental Nonsense and the Functional Approach, 35 Colum. L. Rev. 809 (1935).

${ }^{74}$ Esto proviene del positivismo de Kelsen y su oposición a incluir una declaración de derechos ("normas de derecho natural”) en una constitución. Véase Hans Kelsen, Le garantie juridictionnel de la constitution, 44 Revue de droit public 197 (1928), analizado en Alec Stone Sweet, The Birth Of Judicial Politics In France 228-231 (1992). 
intereses. La aristocracia británica fue singularmente exitosa en ello, logrando negociar su propia renuncia al poder a lo largo de más de un siglo ${ }^{75}$. La aristocracia francesa no lo fue, y cayó en un momento de entusiasmo revolucionario ${ }^{76}$. El discurso acerca de los “intereses especiales" marca el mismo fenómeno en la política norteamericana.

El enemigo del constitucionalismo se encuentra en esta convergencia de insultos políticos: interés, facción, clase. Todos ellos obtienen su significado de la oposición con el bien común, el que está delineado por la razón y afirmado por la voluntad del soberano. Pero aquí es donde el acuerdo empieza a desaparecer. Hay al menos dos caminos abiertos para un tribunal constitucional incluso cuando afirma un conjunto compartido de aspiraciones: el de la justicia y el de la legitimidad.

El constitucionalismo moderno occidental se sustenta en patrones de pensamiento que son tan antiguos como Occidente mismo. Creemos simultáneamente en la universalidad de las normas y en la nación; creemos en la racionalidad y la autonomía, en la justicia y la legitimidad. En el corazón de todas estas antinomias se encuentra la tensión entre razón y voluntad. El constitucionalismo occidental no resuelve esta antinomia, sino que se sitúa a sí mismo dentro de ella, en todas sus variadas formas. No puede resolver este conflicto debido a que no hay una única manera para seguir la égida del derecho. De hecho, si bien la Corte norteamericana ha tenido un singular éxito mediante el camino de la voluntad, es una voz excepcional en el constitucionalismo contemporáneo. La mayoría de los tribunales constitucionales hoy hablan el lenguaje de la razón, de los valores universales, de los juicios situados de razonabilidad. Por supuesto, en una gran variedad de asuntos existe todavía desacuerdo, cualquiera que sea el camino que una corte siga. Pero subsiste una importante división dentro de la cultura jurídica occidental respecto de la concepción del yo y de la comunidad política. Marbury es un modelo; pero no es el único. Su voz se ha transformado en la voz de la cultura jurídica norteamericana. Esa voz no es la voz de la razón: es la voz de la soberanía popular. Otras naciones tienen buenas razones para preferir una voz constitucional de la razón por sobre una de la soberanía popular. Sería muy equivocado de parte de los juristas norteamericanos el instarles a seguir a Marbury.

\section{BIBLIOGRAFÍA}

Aleinikoff, T., Alexander, Constitutional Law in the Age of Balancing, 96 Yale L.J. 943 (1987). Aristotle, The Nicomachean Ethics.

Aharon, Barak, Foreword: A Judge on Judging: The Role of a Supreme Court in a Democracy, 116 Harv. L. Rev. 16 (2002).

BeLL, John, Principles as Methods of Judicial Selection in France, 61 S. Cal. L. Rev. 1757 (1988).

${ }^{75}$ Véase, por ejemplo, David Cannadine, Ornamentalism: How The British Saw Their Empire (2001).

${ }^{76}$ En la noche del 4 de agosto de 1789, la Asamblea Nacional de Francia abolió el feudalismo y todos los provilegios poseídos por la aristocracia. 
Bickel, Alexander M., The Least Dangerous Branch: The Supreme Court At The Bar Of Politics (2d ed. 1986).

Cannadine, David, Ornamentalism: How The British Saw Their Empire (2001).

Cohen, Felix S., Transcendental Nonsense and the Functional Approach, 35 Colum. L. Rev. 809 (1935).

FaLlon, Richard, Foreword: Implementing the Constitution, 111 Harv. L. Rev. 54 (1997).

Goldstein, Joseph, The Intelligible Constitution: The Supreme Court's Obligation To Maintain The Constitution As Something We The People Can Understand (1992).

Habermas, Jürgen, Habermas On Law And Democracy: Critical Exchanges (Michel Rosenfeld \& Andrew Arato eds., 1998).

Haney Lopez, Ian F., White By Law: The Legal Construction Of Race (1996).

Hasday, Jill Elaine, Parenthood Divided: A Legal History of the Bifurcated Law of Parental Relations, 90 Geo. L.J. 299 (2002).

IgnatiefF, Michael, Blood And Belonging: Journeys Into The New Nationalism (1993).

KaHn, Paul W., The Court, the Community and the Judicial Balance: The Jurisprudence of Justice Powell, 97 Yale L.J. 1 (1987).

KaHn, Paul W., Legitimacy and History: Self-Government in American Constitutional Theory (1992).

KaHn, Paul, The Reign of Law: Marbury v. Madison y la Constitución de Estados Unidos (1997).

KaHn, Paul, The Cultural Study of Law: Reconstructing Legal Scholarship (1999).

Kantorowicz, Ernst H., The King's Two Bodies: A Study In Mediaeval Political Theology (1957).

Kelsen, Hans, Le garantie juridictionnel de la constitution, 44 Revue de droit public 197 (1928).

Luhmann, Niklas, The Unity of the Legal System, en Autopoietic Law: A New Approach To Law And Society (Gunther Teubner ed., 1987).

Muller, Ingo, Hitler's Justice: The Courts Of The Third Reich (Deborah Lucas Schneider trans., 1991).

Paine, Thomas, Common Sense (1776), en Political Writings (B. Kuklich ed., 1989).

Michelman, Frank I., The Supreme Court 1985 Term - Foreword: Traces of Self Government, 100 Harv. L. Rev. 4 (1986).

Neiman, Susan, Evil In Modern Thought: An Alternative History Of Philosophy (2002).

Platón, Gorgias (G.P. Goold ed., 1961).

Rivera Ramos, Efren, The Legal Construction Of Identity: The Judicial And Social Legacy Of American Colonialism In Puerto Rico (2001).

Rousseau, Jean-Jacques, The Social Contract (Maurice Cranston ed., Penguin 1968) (1762).

Scalia, Antonin, The Rule of Law as a Law of Rules, 56 U. Chi. L. Rev. 1175 (1989).

ShapIro, Martin, Law and Politics in the Supreme Court: New Approaches to Political Jurisprudence (1964).

Shapiro, Martin y Alec Stone Sweet, On Law, Politics, and Judicialization (2002).

Shetreet, Shimon, Justice In Israel: A Study Of The Israeli Judiciary (1994)

SweEt, Alec Stone, The Birth Of Judicial Politics In France: The Constitutional Council In Comparative Perspective (1992).

SweEt, Alec Stone \& Thomas C. Brunell, Constructing a Supranational Constitution: Dispute Resolution and Governance in the European Community, 92 Am. Pol. Sci. Rev. 63 (1998).

SweEt, Alec Stone, Governing With Judges: Constitutional Politics In Europe (2000).

Unger, Roberto, What Should Legal Analysis Become? (1996).

Weber, Max, The Theory Of Social And Economic Organization (A.M. Henderson \& Talcott Parsons trans., Oxford Univ. Press 1947).

WeILER, J.H.H., The Transformation of Europe, 100 Yale L.J. 2403 (1991). 